\title{
Pemanfaatan Social Traffic untuk Meningkatkan Page Views Pada Video "Gagasan Isengin Acil ! Leri Marah" Di Akun Youtube dan Instagram Dalang Pelo
}

\author{
Gresia Indah Putri, Diah Ayu Candraningrum \\ gresia.915160044@stu.untar.ac.id,diahc@fikom.untar.ac.id
}

Fakultas Ilmu Komunikasi Universitas Tarumanagara

\begin{abstract}
In this digital era, new media such as Instagram and Youtube has become the most popular media, especially among teenagers. With the advanced of these new media, content creators have been using Instagram and Youtube as platform to express ideas, creativity and upload their works. One of favourable content video in Youtube is Dalang Pelo's animated content that is funny and interesting. The creator content that made the video animation, is Nur Alif Ramadhan. The author is interested in analyzing Dalang Pelo's animation because currently there are many video animations with similar content, but it still exist. The purpose of this study is to find out how publisher gets a high page view on Dalang Pelo's Youtube video. The theory used is the New Media Theory which contains the concepts of website traffic, social traffic, and high page views. The research method used is a case study with a qualitative approach. In this study, the author wants to find out how Dalang Pelo's video utilizes social traffic strategy to increase page views on it's Instagram and Youtube accounts through interviews, observations and documentation. The results of this study can be conclude that the creator of Dalang Pelo utilizes two social media which are currently widely used by the community. By converting these media strategically, they can get a high number of page views.
\end{abstract}

Keywords: content creator, high page views, social traffic

\begin{abstract}
Abstrak
Di era digital ini media baru seperti Instagram dan Youtube menjadi media yang paling banyak digemari remaja. Dengan kemunculan media baru ini membuat para konten kreator menggunakan Instagram dan Youtube sebagai tempat untuk menuangkan ide, kreatifitas serta mengunggah hasil karya mereka. Salah satu konten yang saat ini banyak diminati oleh masyarakat adalah konten animasi Dalang Pelo yang lucu dan menarik. Konten kreator yang membuat animasi tersebut adalah Nur Alif Ramadhan. Penulis tertarik untuk menganalisis video animasi Dalang Pelo karena saat ini banyak animasi yang serupa dengan kontennya, tetapi ia tetap mampu bersaing serta mempertahankan eksistensinya. Tujuan dari penelitian ini adalah untuk mengetahui bagaimana publisher mendapatkan pageview tinggi di video Youtube Dalang Pelo. Teori yang digunakan adalah teori Media Baru yang didalamnya berisi konsep traffic website, social traffic, dan page views tinggi. Metode penelitian yang digunakan adalah studi kasus dengan pendekatan kualitatif. Pada penelitian ini penulis ingin mengetahui cara Dalang Pelo memanfaatkan social traffic untuk meningkatkan page views di akun Instagram dan Youtube Dalang Pelo melalui wawancara, pengamatan dan dokumentasi. Hasil penelitian ini dapat disimpulkan bahwa kreator Dalang Pelo memanfaat dua media sosial yang saat ini banyak digunakan masyarakat dengan cara mengkonvergensikan media tersebut sehingga bisa mendapatkan jumlah page view yang tinggi.
\end{abstract}

Kata Kunci: konten kreator, page views tinggi, social traffic 


\section{Pendahuluan}

Di zaman globalisasi saat ini, hampir semua masyarakat telah merasakan hidup di dua dunia, yaitu: dunia kehidupan sehari-hari dan dunia pengguna internet. Kehadiran internet ini banyak dimanfaatkan oleh masyarakat untuk mengakses media sosial, karena dengan media sosial masyarakat bisa dengan bebas untuk berbagi dan mencari informasi serta berkomunikasi dengan orang banyak tanpa banyak hambatan dalam hal biaya, jarak dan waktu (Soliha, 2015).

Konten kreator adalah orang yang membuat sebuah konten, berupa tulisan, gambar, video, suara, ataupun gabungan dari dua atau lebih materi. Konten tersebut dibuat untuk media, khususnya media digital, seperti YouTube, Instagram, Blogger, dan berbagai platform media sosial lainnya. Industri yang dibuat kontennya, mempunyai gaya penulisan yang terkini, berpikir seperti audiens, dan mempunyai jaringan yang luas (Sayugi, 2018). Berdasarkan penelitian Nigar Pandrianto dan Gregorius Genep Sukendro pada penelitian "Analisis Strategi Pesan Content Marketing Untuk Mempertahankan Brand Engagement" bahwa di tengah banyaknya penggunaan media digital sebagai perantara dari komunikasi, hal yang perlu diperhatikan dalam media sosial adalah formulasi konten atau pesan yang akan dikomunikasikan kepada audiens.

Media sosial merupakan konten online yang dibuat sedemikian rupa agar mudah diakses. Dengan adanya teknologi ini memunculkan terjadinya pergeseran dari cara berbagi berita, mencari informasi serta konten. Sosial media yang beroperasi di seluruh dunia saat ini, yakni Facebook, Twitter, Instagram dan Youtube (Badri, 2011).

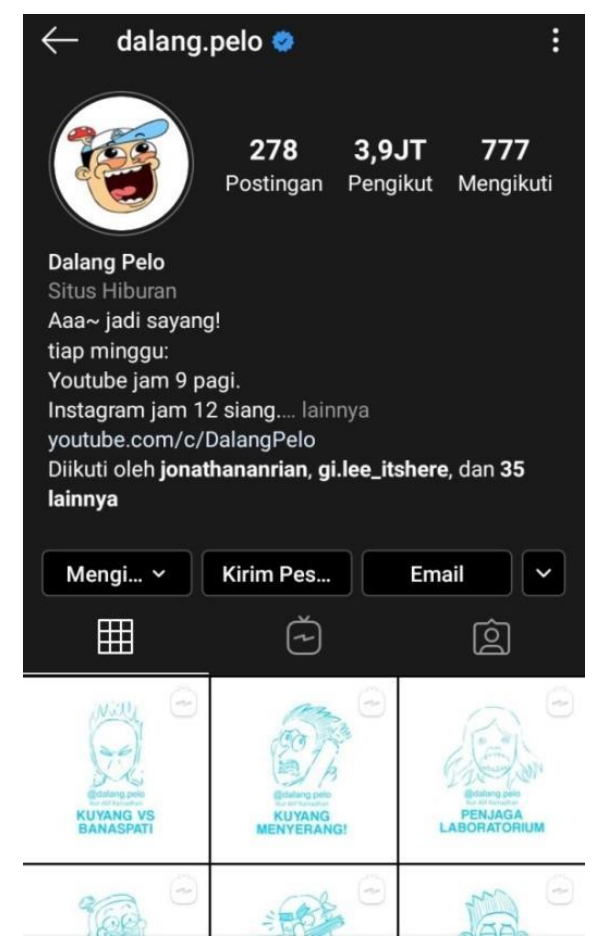

Gambar 1. Instagram Dalang Pelo 


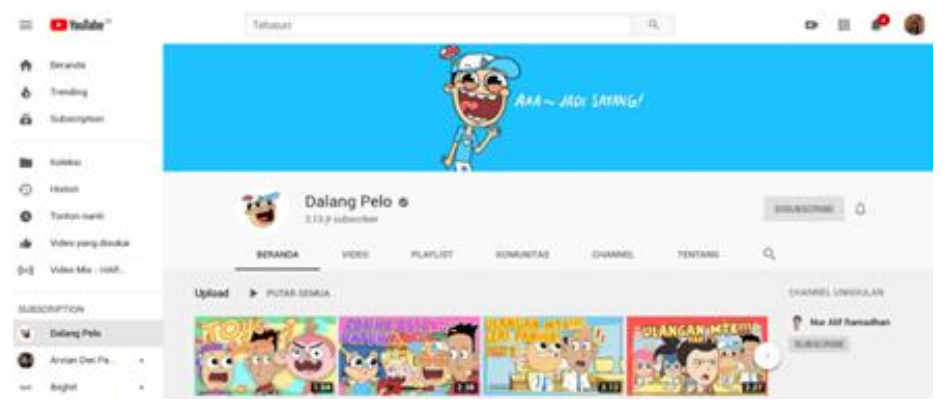

\section{Gambar 2. Timeline Youtube Animasi Dalang Pelo}

Nur Alif Ramadhan adalah konten kreator animasi Dalang Pelo. Dan setiap video unggahan Dalang Pelo di Youtube juga selalu menjadi trending topic. Peneliti ingin membahas animasi Dalang Pelo karena konten tersebut merupakan animasi lucu Indonesia yang memiliki jumlah penonton yang tinggi. Keunikan dari Animasi Dalang Pelo ini adalah memiliki durasi video yang singkat. Kebanyakan yang menonton video Dalang Pelo adalah remaja yang berusia 12 tahun hingga 12 tahun keatas.

\section{Metode Penelitian}

Dalam penelitian ini penulis menggunakan jenis penelitian kualitatif ini adalah metode studi kasus. Studi kasus merupakan metode yang bertujuan untuk mempelajari dan menyelidiki suatu kejadian atau fenomena mengenai individu, seperti riwayat hidup seseorang yang menjadi objek penelitian. Selain itu studi kasus juga membutuhkan banyak informasi dan integrasi data yang diperoleh dari metode lain untuk mendapatkan informasi mendalam pada metode studi kasus yang dilakukan (Walgito, 2010).

Studi kasus memungkinkan untuk menyelidiki suatu peristiwa, situasi, atau kondisi sosial tertentu dan untuk memberikan wawasan dalam proses yang menjelaskan bagaimana peristiwa atau situasi tertentu terjadi (Hodgetts \& Stolte, 2012).

Dalam penelitian ini, metode penelitian yang digunakan penulis adalah fenomenologi dikarenakan peneliti ingin mengetahui dan mengumpulkan informasi lebih lengkap terhadap fenomena tersebut. Melalui metode ini, penulis mengumpulkan informasi dengan wawancara dan studi dokumen terhadap fenomena tersebut.

\section{Hasil Temuan Dan Analisis}

Hasil Temuan Dan Analisis yang ditemukan dalam penelitian ini adalah sebagai berikut: Traffic website adalah jumlah orang yang mengunjungi website, berapa banyak halaman yang mereka lihat, dan durasi saat pengunjung melihat. Angka dari data tersebut akan memperlihatkan seberapa populernya website yang dimiliki dan apa yang harus dilakukan untuk meningkatkan jumlah pengunjung website (Himawan, 2015). Tips yang digunakan Dalang Pelo untuk meningkatkan traffic :

(1) Persiapkan konten dengan matang sebelum publikasi.

(2) Pastikan konten unik, hasil karya sendiri dan up to date.

(3) Pelajari topik yang banyak dikunjungi pengunjung.

(4) Memaksimalkan penggunaan media sosial. 
(5) Memasang link pada semua media sosial yang dimiliki.

Jenis traffic yang digunakan dalam animasi Dalang Pelo adalah

- social traffic : merupakan cara paling ampuh bagi website baru untuk mendapatkan popularitas. Mengingat sebagian besar pengguna internet pasti memiliki akun sosial media dan secara aktif menggunakannya dalam aktivitas sehari-hari.

Tolak ukur dalam social traffic meliputi :

a) Engagement (keterlibatan) : seberapa banyak akun khalayak yang berinteraksi dengan akun anda dan seberapa sering. Setiap jaringan akan memiliki semacam metrik keterlibatan yang merupakan jumlah total metrik keterlibatan yang lebih kecil seperti suka, komentar, dan bagikan.

b) Reach (jangkauan) : adalah jumlah pemirsa yang dimiliki dalam sebuah pos. Biasanya jumlah pengikut ditambah akun yang membagikan jumlah pengikut pos

c) Leads (arahan) : untuk mengkonversi khalayak menjadi pengikut media sosial.

d) Conversions (konversi) : untuk menentukan keberhasilan sebuah konten dari orang mengunjungi akun anda melalui saluran media sosial.

- Pageviews adalah intensitas akses halaman website yang dilakukan oleh para pengunjung. Penghitungan pageviews mencakup semua halaman website. Jika pengunjung melakukan refresh halaman, proses tersebut akan dihitung sebagai tampilan halaman tambahan (talkdgtl, 2019).

Tabel 1. Jumlah likes 5 video tertinggi

\begin{tabular}{|c|c|c|c|c|c|}
\hline $\begin{array}{l}\text { Likes dan } \\
\text { Tayangan }\end{array}$ & $\begin{array}{l}\text { Gagas Isengin } \\
\text { Acil! Leri } \\
\text { Marah! }\end{array}$ & $\begin{array}{l}\text { Kambing } \\
\text { Kuh }\end{array}$ & $\begin{array}{l}\text { Dendam } \\
\text { Anak } \\
\text { Monster } \\
\text { Micin }\end{array}$ & $\begin{array}{l}\text { Acil } \\
\text { Bernyanyi! } \\
\text { Entah Apa } \\
\text { Yang } \\
\text { Merasukimu }\end{array}$ & $\begin{array}{l}\text { Acil } \\
\text { Bertukar } \\
\text { Tubuh } \\
\text { dengan } \\
\text { Leri! }\end{array}$ \\
\hline Instagram & $\begin{array}{l}\text { Likes: } \\
537.103 \\
\text { Tayangan : } \\
2.490 .999\end{array}$ & $\begin{array}{l}\text { Likes: } \\
629.245 \\
\text { Tayangan : } \\
1.928 .913\end{array}$ & $\begin{array}{l}\text { Likes : } \\
\text { 429.612 } \\
\text { Tayangan: } \\
1.713 .476\end{array}$ & $\begin{array}{l}\text { Likes: } \\
\text { 408.089 } \\
\text { Tayangan : } \\
701.896\end{array}$ & $\begin{array}{l}\text { Likes : } \\
\text { 175.377 } \\
\text { Tayangan : } \\
626.245\end{array}$ \\
\hline Youtube & $\begin{array}{l}\text { Likes : } \\
91.000 \\
\text { Tayangan : } \\
4.931 .135\end{array}$ & $\begin{array}{l}\text { Likes: } \\
127.000 \\
\text { Tayangan : } \\
4.541 .687\end{array}$ & $\begin{array}{l}\text { Likes: } \\
87.000 \\
\text { Tayangan : } \\
4.366 .688\end{array}$ & $\begin{array}{l}\text { Likes: } \\
152.000 \\
\text { Tayangan : } \\
4.520 .539\end{array}$ & $\begin{array}{l}\text { Likes: } \\
60.000 \\
\text { Tayangan : } \\
4.345 .262\end{array}$ \\
\hline
\end{tabular}

Sumber : Data Kompilasi Pribadi

Analisis dari penelitian di atas adalah di era digital saat ini semakin banyak bermunculan berbagai macam media baru, seperti : Instagram, Youtube, Twitter dan Facebook. Dan dengan kemunculan berbagai media baru tersebut membuat para konten kreator semakin banyak mengeluarkan ide serta kreatifitas mereka.

Dalam membuat sebuah konten biasanya konten kreator juga memadukan unsur untuk menghibur, mengedukasi, atau bahkan menginformasi. Dibalik konten yang dibuat seseorang pasti ada tujuan yang ingin dicapai atau pesan yang ingin disampaikan. Jadi untuk membuat sebuah konten harus dirancang sedemikian rupa agar penonton yang melihat konten tersebut juga mengerti apa isi atau pesan yang ingin disampaikan. 
Dalang Pelo merupakan animasi Indonesia yang dibuat dan dikelola oleh seorang remaja yang bernama Nur Alif Ramadhan. Karakter yang terdapat dalam Dalang Pelo ada empat, yaitu: Acil, Om Gepeng, Kane dan Leri. Pada setiap karakter yang dibuat memiliki ciri khas yang berbeda - beda.

Animasi Dalang Pelo yang dibuat oleh Nur Alif Ramdhan merupakan konten yang menghibur sekaligus mengedukasi untuk masyarakat yang menonton. Proses pembuatan satu video animasi membutuhkan waktu sekitar lima hari. Ia juga memiliki jadwal rutin dalam mengunggah video setiap minggunya agar semakin hari penontonnya semakin bertambah.

Melihat perkembangan teknologi saat ini Nur Alif Ramadhan memanfaatkan media baru seperti: Instagram dan Youtube untuk mengunggah animasi Dalang Pelo. Ia menggunakan kedua media tersebut karena ia melihat banyaknya masyarakat yang memiliki dan mengakses media itu. Sehingga hal ini dapat dijadikan peluang untuk bertambahnya jumlah penonton.

Dalang Pelo menggunakan konsep social traffic yang dimana kreator menggunakan dua media sosial yang dimiliki untuk mengunggah dan mengingatkan bahwa akan ada video baru yang akan tayang. Media baru yang digunakan adalah Instagram dan Youtube. Ia menggunakan media tersebut karena banyak masyarakat yang menggunakanya.

Melalui media Instagram kreator animasi tersebut akan mengunggah sedikit cuplikan video yang akan tayang dalam bentuk video atau Instagram tv, sedangkan di Youtube kreator mengunggah video yang utuh. Jadi apabila penonton yang ingin menonton yang ingin menonton video utuhnya bisa langsung beralih ke Youtube Dalang Pelo. Dengan menerapkan cara social traffic ini ia berhasil mendapatkan jumlah penonton yang tinggi bahkan views untuk satu videonya dapat mencapai jutaan tayangan.

\section{Simpulan}

Hasil pembahasan dan penelitian pada bab sebelumnya peneliti menyimpulkan bahwa : Pemanfaatan social traffic di era globalisasi ini sangat mempengaruhi sebuah konten untuk meningkatkan pageviews. Banyak pemilik media televisi dan konten kreator yang menggunakan konsep ini dikarenakan saat ini banyak masyarakat yang menggunakan media sosial. Hal ini terjadi karena media sosial dapat diakses kapan dan dimanapun berada.

Kelebihan yang terdapat dari penggunaan social traffic adalah terdapat data statistik. Data statistik yang dimaksud disini adalah untuk melihat bagaimana perkembangan jumlah penonton di setiap video unggahannya. Dengan adanya hal ini konten Dalang Pelo bisa semakin menyesuaikan cerita dan meningkatkan jumlah penonton di setiap unggahannya. Kaitan penelitian ini dengan jurnalistik sebagai peminatan peneliti adalah:

- Dalam hal media baru : Media baru merupakan media yang satu-satunya menjadi perantara dalam mencari informasi, mempublikasikan kreasi seseorang baik dalam bentuk tulisan atau blog, gambar, ataupun video. Namun dibalik itu penggunaan media baru juga harus dipahami sebagai proses transformasi akan kebutuhan informasi.

- Dalam jurnalistik penggabungan berbagai media kini pemilik media banyak yang mendistribusikan konten mereka dari media konvensional seperti TV, radio, dan media cetak ke media online. Dengan adanya media online, ia dapat 
mengolah beritanya menjadi video, galeri foto, dan ruang berita yang lebih luas dibandingkan versi cetak. Selain meningkatkan kapasitasnya, hal ini juga dapat meningkatkan interaktivitas dengan pembaca.

\section{Ucapan Terima Kasih}

Penulis mengucapkan terima kasih kepada narasumber ahli media sosial, narasumber kunci (kreator Dalang Pelo), serta narasumber yang menonton video animasi Dalang Pelo di media Instagram, Youtube, atau bahkan kedua media tersebut. Karena narasumber diatas telah bersedia penulis wawancarai sehingga informasi dan data yang dibutuhkan dalam penelitian dapat terkumpul. Selain itu penulis berterima kasih juga untuk Fakultas Ilmu Komunikasi Universitas Tarumanagara dan pihak yang bersangkutan dalam penelitian ini.

\section{Daftar Pustaka}

Badri, Muhammad. (2011). Corporate Marketing and Communication. Jakarta Universitas Mercu Buana.

Creswell, J. W. (2010). Research design: pendekatan kualitatif, kuantitatif, dan mixed. Yogjakarta: PT Pustaka Pelajar.

Himawan, Arisantoso \& Saefullah, A. (2015). Analisa Pengaruh Penggunaan Search Engine Optimization (SEO) Pada Website E-Commerce. Proceedings in Seminar Nasional Sistem Informasi Indonesia (SESINDO).

Kuswarno, Engkus (2009). Metedologi Penelitian Komunikasi Fenomenologi; Konsepsi, Pedoman, dan Contoh Penelitian, Bandung: Widya Padjajaran.

Pandrianto, Nigar \& Gregorius Genep Sukendro. (2018). Analisis Strategi Pesan Content Marketing Untuk Mempertahankan Brand Engagement. Volume 10, Nomor 2. Sayugi. (2018). Content Creator dalam Kacamata Industri Kreatif : Personal Branding Dalam Media Sosial. Diakses pada tanggal 10 Oktober 2019 pukul 18.45 WIB. Terarsip di: http://repository.unpar.ac.id/bitstream/handle/123456789/7824/maklhsc472 Daniel_Content $\% 20$ creator-p.pdf?sequence $=1$ \&isAllowed $=\mathrm{y}$

Soliha. (2015). Tingkat ketergantungan pengguna media sosial dan kecemasan sosial. Jurnal Interaksi.

Walgito, Bimo. (2010). Bimbingan dan Konseling Studi \& Karir. Yogjakarta: Andi. 